\title{
Incidence of Cardiovascular Events after Nephrectomy - A Single Centre, Matched Pair Analysis between Donor and Tumour Nephrectomy in a Long Term Follow-Up
}

\author{
Sebastian Nestler ${ }^{\mathrm{a}, \mathrm{b}}$ Patrick Levien $^{\mathrm{a}}$ Andreas Neisius $^{\mathrm{a}}$ Christian Thomas $^{\mathrm{a}, \mathrm{c}}$ \\ Mohammed M. Kamal ${ }^{a}$ Christian Hampel ${ }^{a}$ Jon Jones ${ }^{b}$ Joachim W. Thüroffa, d \\ Frederik C. Roos ${ }^{\mathrm{a}, \mathrm{c}}$ \\ Departments of Urology a Medical Centre, Johannes Gutenberg University, Mainz, ${ }^{b}$ Hochtaunus-Kliniken, Bad \\ Homburg, ' University of Frankfurt, Frankfurt, and d University of Mannheim, Medical Faculty of University of \\ Heidelberg, Mannheim, Germany
}

\section{Key Words \\ Cardiovascular events $\cdot$ Kidney donation $\cdot$ Long term follow-up - Loss of kidney function · Nephrectomy . Glomerular filtration rate}

\begin{abstract}
Introduction: The study aimed to compare the incidence of cardiovascular events (CVEs) after donor nephrectomy (DN) and radical tumor nephrectomy (RN), according to an estimated glomerular filtration rate (eGFR), were evaluated over time. Materials and Methods: Follow-up was collected for DN who underwent surgery from 1998 to 2007 for CVE and renal function. All DN were matched for age to patients treated by RN or adenoma enucleation (control group), who were eligible for DN. eGFR was estimated using the CockgroftGould formula. Patients with preoperative comorbidities were excluded. Results: Thirty DN (median age 48.9 years) were included with a median follow-up of 138.5 months (interquartile range 119-159). No significant differences in patients' characteristics were found preoperatively ( $p>0.5$ ). Four out of $30 \mathrm{DN}$ developed a CVE (3 myocardial infarctions (MI), 1 stroke), 2 of 30 patients in the control group (both MI)
\end{abstract}

and 8 of 30 RN patients ( $6 \mathrm{Ml}, 2$ strokes, $\mathrm{p}>0.05)$. Arterial hypertension developed in $14 \mathrm{DN}(46.7 \%)$, in 12 (40\%) after RN and in 15 controls. The CVE occurred after a median time of 68 months (5-231) and were related to a drop of $\sim 30 \%$ in the eGFR irrespective of the group. Conclusion: Decline of renal function after nephrectomy is the main risk factor for CVE. Close monitoring of renal function and new onset hypertension is warranted.

(c) 2016 S. Karger AG, Basel

\section{Introduction}

Nephrectomy is a common procedure in urology due to different reasons. International guidelines recommend radical nephrectomy (RN) for large and complex renal cell carcinomas ( $>\mathrm{cT} 1 \mathrm{~b}$ ), which are not eligible for nephron sparing surgery [1]. Benign reasons for nephrectomy comprise functional kidneys due to, for example, hydronephrosis or stone disease. A very delicate indication is living kidney donation (DN), since it is an altruistic deed and risks should be carefully evaluated in advance.

\section{KARGER}

E-Mail karger@karger.com

www.karger.com/uin
C 2016 S. Karger AG, Basel

0042-1138/16/0972-0142\$39.50/0 
The removal of a kidney may lead to reduced renal function by the loss of functional parenchyma and the development of end stage renal disease (ESRD) [2], defined as estimated glomerular filtration rate (eGFR) $<40 \mathrm{ml} / \mathrm{min} / 1.73 \mathrm{~m}^{2}$ body surface [3]. In the general population, an association between reduced renal function without regarding the causes and an increased risk of cardiovascular events (CVEs) has been described $[2,4]$ as well as an increase of blood pressure [3].

Not surprisingly, large studies could state the same facts for RN [5]. Elevated incidence of CVEs could be described for patients after $\mathrm{RN}$ compared to the general population ( $\mathrm{p}<0.001)[6]$, most likely due to the development of ESRD $[7,8]$.

Death rates for patients undergoing $\mathrm{DN}$ were shown to be similar - 30 days, 1 year and 15 years after surgery to a healthy matched cohort ( 0.04 vs. $0.06 \% ; \mathrm{p}=0.11)$ [9]; this observation could also be shown in a cohort of older donors matched to non-donors $(p=0.70)$ [10]. ESRD was even proven to be lower in patients after $\mathrm{DN}$ compared to the general population (180 vs. 268 per million persons per year) [11]. Nevertheless, opinions differ, when discussing the incidence of CVEs after DN. Several studies comparing cardiovascular mortality in kidney donors to the general population stated no higher risk for kidney donors [9, 11-13]. Furthermore, no higher incidence of hypertension for patients was found after DN compared to the general population in a study by Garg et al. [14] comprising 2,028 kidney donors. The incidence of myocardial infarction (MI) and stent implantation in the coronary arteries or strokes were stated to be identical to the general population [14]. However, Mjoen et al. [15] showed an increased risk of ESRD and cardiovascular death $(30.4 \%$ of all deaths in the donor group vs. $28.4 \%$ in the control group; $\mathrm{p}=0.03$ ) and a significant increased risk in all-cause mortality for patients 15 years after DN in comparison to a general population cohort eligible for kidney donation $(\mathrm{p}<0.001)$.

The aim of our study was to compare the incidence of CVEs and ESRD in patients after DN to a cohort of patients treated by $\mathrm{RN}$ for renal cell cancer and to a control group of patients undergoing adenoma enucleation, who would be eligible for donor nephrectomy (DN).

\section{Material and Methods}

All patients, who underwent DN at our institution between 1998 and 2007, were called by telephone in August 2014 and interviewed for CVEs (MI, peripheral arterial disease, stroke) and new- ly diagnosed arterial hypertension $(\mathrm{aH})$ since surgery. These parameters were used since they can be correlated to a certain date and easily enquired during a telephone interview. For this reason, we decided against coronary heart disease as a parameter, because it is slowly progressing. Last serum creatinine was documented for the last 6 months from the interview date. Patient files were searched for preoperative creatinine levels and for comorbidities possibly affecting the kidney or heart function like diabetes, hypertension, recurrent nephritis of any kind in the patients' history, neurogenic voiding disorders or any kind of heart disease and MI before surgery. Patients in all groups were excluded from the analysis, when any of these cardiovascular or kidney diseases were reported before surgery.

eGFR was estimated preoperatively and at time of follow-up using the Cockgroft-Gould formula.

All kidney donors were matched for age at the time of surgery to patients who had undergone RN at our institution for clear-cell renal cell carcinoma pT1 between 1990 and 1999. Healthy patients treated by open adenoma enucleation of a prostate adenoma, who would be eligible for a DN, served as a control group. All patients in these groups already had a complete follow-up due to phone interviews in 2013 and 2014 for different surveys. Since these patients had a follow-up longer than 138.5 months, it was reduced to be comparable to the follow-up of the kidney donors. CVEs were excluded, when they occurred later than the end of the reduced follow-up time. Serum creatinine levels were used to calculate the eGFR using the Cockgroft-Gould formula.

Continuous variables were reported as median value and interquartile ranges (IQRs) Normal distribution of continuous parameters such as age and follow-up period were tested using the unpaired t test. As this is an exploratory study and no adjustment for multiple testing was done, $\mathrm{p}$ values are descriptive only and $\mathrm{p}<$ 0.05 was considered to indicate significant differences. All statistical analyses were performed using SPSS 22.0.

\section{Results}

Between 1998 and 2007, 33 kidney donations were performed at our institution of which 30 donors could be contacted (15 men, 15 women). Data files were complete in all patients. For the whole study cohort, median age was 48.9 years (IQR 46-56) and median follow-up was 138.5 months (IQR 119-159). The clinical characteristics are shown in table 1 . The groups did not differ significantly in age and time of follow-up. Eighteen patients after $\mathrm{RN}$ were men and 12 were women.

\section{Cardiovascular Events}

Of the contacted 30 kidney donors, 4 (13.3\%) patients developed a CVE, 3 patients developed a MI and 1patient developed stroke. At the time of the event, 2 patients were older than 60 years and 2 patients were younger. In the group of patients after RN, 8 (26.7\%) patients developed a CVE. Six patients suffered from a MI, 2 from a stroke. 
Table 1. Median age and follow-up time in the different study arms. The mentioned p value describes the differences over all 3 groups

\begin{tabular}{lcccc}
\hline & DN & RN & Control group & p value \\
\hline Age, years, median (IQR) & $48.9(46-56)$ & $53.7(46-57)$ & $51.3(43-58)$ & 0.65 \\
Follow-up time, months, median (IQR) & $138.5(119-159)$ & $151(143-177)$ & $147(122-161)$ & 0.88 \\
\hline
\end{tabular}

One of these patients was younger than 60 years at the time of the event. In the group of patients treated by open adenoma enucleation of the prostate (control group), 2 patients who were older than 60 years suffered from MI (6.7\%). In comparison to the incidence of CVEs in the general population $(10.5 \%$ for people between 50 and 65 years) [16], there was no significant difference to the donor group $(13.3 \%, \mathrm{p}=0.87)$ and the control group $(6.6 \%, p=0.77)$. In contrast, the group of patients undergoing $\mathrm{RN}$ showed a significant higher incidence $(26.7 \%$, $\mathrm{p}=0.02)$. The events occurred at a median time of 50 months after DN, 121 months after RN and 81 months after adenoma enucleation.

The incidence of aH was comparable in all groups. After DN, 14 patients $(46.7 \%)$ reported a newly diagnosed and treated $\mathrm{aH}$; after RN, 12 patients (40\%) and 15 (50\%) patients in the control group developed $\mathrm{aH}$. In the general population, the incidence of $\mathrm{aH}$ is described to be around $45 \%$ [16]. The difference reached no significance $(\mathrm{p}=0.79$ overall $)$.

\section{Renal Function}

eGFR was estimated for all patients preoperatively and at the time of follow-up. In the group of kidney donors eGFR subsided non-significantly from $74.3 \mathrm{ml} /$ $\mathrm{min} / 1.73 \mathrm{~m}^{2}$ body surface to $62.7 \mathrm{ml} / \mathrm{min} / 173 \mathrm{~m}^{2}$ body surface; in the control group, almost no decline of renal function was measurable. Again in contrast, patients after $\mathrm{RN}$ almost reached significance in reduction of eGFR. None of the patients suffered from ESRD or had to undergo dialysis. Renal function including the eGFRs preoperatively and at the time of latest follow-up is summarized in table 2.

\section{Patients with CVEs}

To evaluate the impact of decline of renal function, we evaluated all patients with a CVE for renal function and compared them to the patients in the corresponding group without a CVE. The CVEs occurred after a median time of 68 months (5-231). Two of the patients with CVE after DN were female and 1 was male. The patient with a stroke was female. Two patients were older than 60 years at the time of the event, 2 younger. Median eGFR was preoperatively $82.2 \mathrm{ml} / \mathrm{min} / 1.73 \mathrm{~m}^{2}$ body surface and declined by $28.8 \%$ to $58.5 \mathrm{ml} / \mathrm{min} / 1.73 \mathrm{~m}^{2}$ body surface compared to $15.6 \%$ in the whole group $(\mathrm{p}=$ 0.03 ). Four of the patients with MI after RN were men and 2 were women. One woman was younger than 60 years at the time of event. The 2 patients who developed stroke were men. Median eGFR was preoperatively $64.1 \mathrm{ml} / \mathrm{min} / 1.73 \mathrm{~m}^{2}$ body surface and declined by $33.3 \%$ to $42.7 \mathrm{ml} / \mathrm{min} / 1.73 \mathrm{~m}^{2}$ body surface compared to $15.6 \%$ in the whole group $(p=0.02)$. In the control group, both patients with MI were older than 60 years at time of event, renal function had decreased by $10.2 \%$, which was not significant compared to the decline in the remaining patients of the group $(\mathrm{p}=0.77)$. Table 3 shows patients who suffered from a CVE in relation to their preoperative eGFR and their renal function at the time of the event.

\section{Discussion}

The aim of this study was to compare 2 groups of patients after nephrectomy both having an elevated incidence of CVEs in the long-term follow-up after surgery $[6,15]$ and to weigh the incidence against each other. The decay of eGFR has been described as $13.98 \%$ in a 1 -year follow-up [17] and 25.5\% after RN in a 4.9 -year follow-up [18] or $0.7 \%$ of eGFR per year [19] without regarding the incidence of CVEs, but no data are available for patients after DN. To our knowledge, this study is the first to compare patients after DN and RN for the decline of eGFR and the incidence of CVEs.

For patients after RN, our data support the leading opinion in the literature, which describes an elevated incidence of CVEs after surgery [6]. In our study, we found an incidence for CVEs of $26.6 \%$ for patients treated by $\mathrm{RN}$, which is significantly higher than in the group of patients treated by open adenoma enucleation, which was eligible for DN (6.6\%). As suspected, the 2 
Table 2. eGFR preoperatively and at time of follow-up according to the different study arms

\begin{tabular}{lllll}
\hline & DN & RN & Control group & p value \\
\hline eGFR preoperatively, median (IQR) & $74.3(71.4-94.2)$ & $71.1(68.2-93.9)$ & $72.1(69.7-96.1)$ & 0.65 \\
eGFR at follow-up, median (IQR) & $62.7(56.3-83.6)$ & $53.4(48.3-70.2)$ & $70.2(66.3-94.1)$ & 0.11 \\
p value & 0.21 & 0.06 & 0.88 & \\
\hline
\end{tabular}

Table 3. Patients with CVEs according to time of appearance and renal function

\begin{tabular}{lllllllll}
\hline Patient & Gender & Group & $\begin{array}{l}\text { Age at } \\
\text { surgery }\end{array}$ & $\begin{array}{l}\text { Renal function } \\
\text { preoperatively }\end{array}$ & Event & $\begin{array}{l}\text { Age at } \\
\text { event }\end{array}$ & $\begin{array}{l}\text { Time of event } \\
\text { (months in } \\
\text { follow-up) }\end{array}$ & $\begin{array}{l}\text { Renal } \\
\text { function at } \\
\text { time of } \\
\text { follow-up }\end{array}$ \\
\hline N.G. & Female & DN & 46 & 80.7 & MI & 58 & 146 & 61.6 \\
H.H. & Male & DN & 60 & 65.5 & MI & 60 & 6 & 56.3 \\
I.G. & Female & DN & 56 & 105.4 & MI & 62 & 68 & 55.6 \\
G.A. & Female & DN & 45 & 83.6 & Stroke & 53 & 41 & 65.5 \\
I.W. & Female & RN & 46 & 68.2 & MI & 56 & 120 & 67.9 \\
W.B. & Male & RN & 64 & 53.1 & MI & 86 & 231 & 37.1 \\
E.M. & Male & RN & 58 & 70.9 & MI & 63 & 61 & 56.3 \\
G.H. & Male & RN & 49 & 72.2 & MI & 63 & 165 & 47.2 \\
G.D. & Male & RN & 51 & 71.2 & MI & 61 & 122 & 42.1 \\
H.P. & Male & RN & 61 & 49.4 & MI & 74 & 39 & 65.3 \\
A.G. & Female & RN & 59 & 82.6 & Stroke & 67 & 5 & 43.3 \\
W.-J.K. & Male & RN & 67 & 66.8 & Stroke & 67 & 6 & 49.3 \\
P.S. & Male & AE & 55 & 71.1 & MI & 66 & 117 & 65.0 \\
M.T. & Male & AE & 65 & 65.2 & MI & 69 & 51 & 57.7 \\
\hline
\end{tabular}

Table 4. Overview over the current literature examining risks of kidney donation in a long-term follow-up

\begin{tabular}{llllll}
\hline & $\begin{array}{l}\text { Number } \\
\text { of donors }\end{array}$ & $\begin{array}{l}\text { Follow-up, } \\
\text { years }\end{array}$ & $\begin{array}{l}\text { Elevated cardiovasc } \\
\text { ular complication }\end{array}$ & $\begin{array}{l}\text { Elevated } \\
\text { mortality in } \\
\text { kidney donors }\end{array}$ & $\begin{array}{l}\text { Elevated risk } \\
\text { for ESRD } \\
\text { in donors }\end{array}$ \\
\hline Segev et al. [9], 2010 & 9,364 & 6.4 & $\mathrm{n} / \mathrm{a}$ & No & $\mathrm{n} / \mathrm{a}$ \\
\hline Ibrahim et al. [11], 2009 & 3,968 & 12.2 & $\mathrm{n} / \mathrm{a}$ & No & No \\
\hline Fehrman-Ekholm et al. [12], 1997 & 573 & 14 & $\begin{array}{l}\text { Yes (hypertension) } \\
\text { No (Stroke, MI) }\end{array}$ & n/a & No \\
\hline Okamoto et al. [13], 2010 & 444 & 7 & n/a & No & No \\
\hline Mjoen et al. [15], 2014 & 1,901 & 15.1 & Yes & Yes & Yes \\
\hline
\end{tabular}

cases in this group comply with the incidence in general population and were not related to a reduced renal function.

Concerning CVEs after DN, the opinions in the literature differ in recently published papers. Most papers were comparing patients after $\mathrm{DN}$ with the general population and found no higher incidence for CVEs or cardiovascular mortality [10, 12-14]. In contrast, Mjoen et al. [15] described an increased risk for ESRD and myocardial death for patients after DN in a 15-year follow-up compared to a group of patients eligible for kidney donation meeting the strict criteria as possible candidates for $\mathrm{DN}$. 
The most relevant papers addressing renal function and cardiac events are listed in table 4.

Our data could not support this latest opinion for kidney donors. We found no significantly elevated incidence for CVEs compared to a group of patients eligible for DN, which may be due to our small patient cohort. Herein, more data are needed. We postulate that a prospective study with patients after DN matched for age and comorbidities to patients eligible for kidney donation with yearly controls of GFR and cardiovascular risk factors could provide the necessary data and furthermore help in deciding which pathology appears first. Up to now, there is no available data describing the decline of renal function being caused by CVEs or vice versa.

Even though the incidence of CVEs in the 2 groups after nephrectomy differed almost significantly, we think this observation is due to a bias, since we could show that the patients with CVEs had significantly worse renal function than the rest of the corresponding group (tables 2 and 3). The decline of eGFR in all patients with a CVE was $2.6 \%$ per year. Patients without CVE in contrast lost $1.3 \%$ of eGFR per year and a decline of $0.7 \%$ per year are described in the literature for patients after RN [19]. In our study, the cause for CVEs was the drop of eGFR over the years. Most patients with CVEs showed a decline of GFR between 28 and $35 \%$. These findings support the current opinion in literature $[5,6]$.

The observation that almost significance was reached between the groups (DN vs. RN) seems to be due to the fact that patients for DN can be selected very carefully. Therefore, a better renal function can be expected beforehand to meet the strict criteria for kidney donation, whereas patients for RN have to undergo surgery in order to be cured from the tumor irrespective of their renal function, when a nephron sparing approach cannot be performed. Although small differences in preparation can be expected, the mode of surgery (DN vs. $\mathrm{RN}$ ) seems to have no impact. Even though no patient developed ESRD, reduced renal function seems to be the main risk factor for developing CVEs after nephrectomy. We postulate that a close monitoring of renal function after nephrectomy and the immediate treatment of a new onset of hypertension could reduce the incidence of CVEs. Furthermore, measurement of the thickness of the wall of the internal carotid artery can be used for screening and evaluation of new onset risk for CVEs, since an increased thickness of the intima media by $0.1 \mathrm{~mm}$ displays an increased risk for MI by $10-15 \%$ and for stroke by $13-18 \%$ [20]. All patients after nephrectomy could undergo this simple procedure to prevent CVEs. But nevertheless, further studies with larger case numbers are needed.

\section{Conclusion}

The incidence of CVEs after RN seems to be higher compared to DN, but is most likely only due to the selection of patients eligible for DN, who generally have a better renal function preoperatively. Irrespective of the surgery performed, all patients, who had developed a CVE, showed a decline of renal function above the ordinary compared to the rest of the group.

\section{Disclosure Statement}

There is no conflict of interest for any of the authors.

\section{References}

1 Van Poppel H, et al: A prospective, randomised EORTC intergroup phase 3 study comparing the oncologic outcome of elective nephron-sparing surgery and radical nephrectomy for low-stage renal cell carcinoma. Eur Urol 2011;59:543-552.

$\checkmark 2$ Chronic Kidney Disease Prognosis Consortium, Matsushita K, et al: Association of estimated glomerular filtration rate and albuminuria with all-cause and cardiovascular mortalityingeneral population cohorts: a collaborative meta-analysis. Lancet 2010;375:2073-2081.

$>3$ National Kidney Foundation: K/DOQI clinical practice guidelines for chronic kidney disease: evaluation, classification, and stratification. Am J Kidney Dis 2002;39(2 suppl 1):S1-S266.
4 Girndt M, Trocchi P, Scheidt-Nave C, Markau S, Stang A: The prevalence of renal failure results from the German health interview and examination survey for adults, 2008-2011 (DEGS1). Dtsch Arztebl Int 2016;113:85-91.

$\checkmark 5$ Go AS, et al: Chronic kidney disease and the risks of death, cardiovascular events, and hospitalization. N Engl J Med 2004;351:12961305.

$\checkmark 6$ McKiernan J, et al: Natural history of chronic renal insufficiency after partial and radical nephrectomy. Urology 2002;59:816-820.

$>7$ Sarnak MJ, et al: Kidney disease as a risk factor for development of cardiovascular disease: a statement from the American heart association councils on kidney in cardiovascular dis- ease, high blood pressure research, clinical cardiology, and epidemiology and prevention. Hypertension 2003;42:1050-1065.

$>8$ Huang WC, et al: Chronic kidney disease after nephrectomy in patients with renal cortical tumours: a retrospective cohort study. Lancet Oncol 2006;7:735-740.

$>9$ Segev DL, et al: Perioperative mortality and long-term survival following live kidney donation. JAMA 2010;303:959-966.

10 Reese PP, et al: Selecting appropriate controls for kidney donors - reply. Am J Transplant 2015;15:287-288.

11 Ibrahim HN, et al: Long-term consequences of kidney donation. N Engl J Med 2009;360: 459-469. 
12 Fehrman-Ekholm I, et al: Kidney donors live longer. Transplantation 1997;64:976978.

13 Okamoto M, et al: The consequences for live kidney donors with preexisting glucose intolerance without diabetic complication: analysis at a single Japanese center. Transplantation 2010;89:1391-1395.

14 Garg AX, et al: Cardiovascular disease in kidney donors: matched cohort study. BMJ 2012; 344:e1203.
15 Mjoen G, et al: Long-term risks for kidney donors. Kidney Int 2014;86:162-167.

16 Neuhauser H, Thamm M, Ellert U: Blutdruck in deutschland 2008-2011. Ergebnisse der studie zur gesundheit erwachsener in eutschland (DEGS1). Bundesgesundheitsblatt Gesundheitsforschung Gesundheitsschutz 2013; 56:795-801.

17 Krebs RK, Andreoni C, Ortiz V: Impact of radical and partial nephrectomy on renal function in patients with renal cancer. Urol Int 2014;92:449-454.
18 Roos FC, et al: Functional analysis of elective nephron-sparing surgery vs radical nephrectomy for renal tumors larger than $4 \mathrm{~cm}$. Urology 2012;79:607-613.

19 Demirjian S, et al: Chronic kidney disease due to surgical removal of nephrons: relative rates of progression and survival. J Urol 2014;192: 1057-1062.

20 Lorenz MW, et al: Prediction of clinical cardiovascular events with carotid intima-media thickness: a systematic review and meta-analysis. Circulation 2007;115:459-467. 